\title{
Photoinduced reactions in zeolites: kinetic motion, environment, and charge stabilization
}

\author{
J. K. Thomas \\ University of Notre Dame, Notre Dame, IN 46556
}

\begin{abstract}
Photophysical and photochemical methods are used to examine the interior surfaces of zeolite $X$ and Y. These methods are also used to examine the effect of co-adsorbed solvent molecules on photo-induced processes in these zeolites. In particular, the effect of solvent on the diffusive motion in and between the zeolite cages is illustrated. Finally, the unique charge trapping and charge stabilization of the zeolite is shown.
\end{abstract}

\section{INTRODUCTION}

Microporous zeolites are one of the most important materials used in industry for catalysis, adsorption, and ion exchange [1-4]. The use of this type of materials is expanding, and attempts have been made on many aspects of their applications [5-21]. Studies on the trapping of electrons by charge-balancing cation clusters and by guest species in the zeolite cavities has been active in recent years due to interest in the confinement of zeolite cavities, metal-to-insulator transitions $[8,9$, 14]. charge transfer and stabilization [5, 18], solar energy conversion [6], and base-catalyzed reactions [7].

In the field of photochemistry, the previous two decades have seen extensive use of zeolites, as media for producing molecular photochemistry [22] and other photo-induced molecular processes including phosphorescence [23], electron transfer [16, 19, 25], and energy transfer $[27,28]$. The advantage of using zeolites as a photochemical medium lies in the development of theories of reactivity leading to more predictable chemistry and molecular behavior in zeolites, and often reactions can be carried out with high product selectivity. This is important for the application of zeolites in fine chemical synthesis, where high-temperature activation can lead to thermal decomposition of reactants and products. The photochemical approach also provides a means to examine the kinetics of early events in the reaction mechanism, by use of pulsed excitation sources and rapid detection electronics. Thus, a detailed description of the reaction mechanism is possible.

A popular tool used in studies of photophysics and photochemistry in zeolites has been fluorescence spectroscopy. Here, the approach involves adsorbing a molecular probe to the internal surface of the zeolite and monitoring its fluorescence emission by steady-state and time-resolved approaches. From the characterization of emission spectra and quenching dynamics, the polarity [29, 30] and heterogeneity [31] of the zeolite medium has been characterized as well as molecular processes including dimerization [32-34], access to probes by molecular oxygen $\left(\mathrm{O}_{2}\right)$, and the formation of charge-transfer complexes [16, 35].

At this stage it is important to consider the structure of a zeolite.

\section{ZEOLITE STRUCTURE}

Figure 1 shows a schematic drawing of the zeolite framework structures together with the possible cation sites. The building block of zeolites A, X, and Y is the sodalite cage, pictured as one of the small cages in Figure 1 . The sodalite cage has a structure of a truncated octahedral with $\mathrm{Si}^{4+}$ and $\mathrm{Al}^{3+}$ at the tetrahedral sites and possesses eight hexagonal windows and six square windows. Zeolite A ( $\mathrm{Si} / \mathrm{Al}$ ratio $=1.0)$, a synthetic material with no natural counterpart [1], is a simple cubic array of sodalite cages connected by the square double-four-membered rings (D4R) of $\mathrm{SiO}_{4}^{4-}$ and $\mathrm{AlO}_{4}^{5-}$. There are three different types of cages in zeolite $\mathrm{A}$, i.e., D4R, sodalite cage, and $\alpha$-cage. The cation locations are found to be on the site $\mathrm{A}$ in the center of the six-membered ring of sodalite cage and the site $\mathrm{E}$ on the window of the eight-membered ring. ZK-4 is also a synthetic zeolite formed in the presence of tetramethylammonium ion and isostructural to zeolite A but of higher framework $\mathrm{Si} / \mathrm{Al}$ ratio (Kerr, 1966). Both zeolites $\mathrm{X}$ and $\mathrm{Y}$, having different framework $\mathrm{Si} / \mathrm{Al}$ ratios ( $>1.5$ for zeolite $\mathrm{Y}$ and $<1.5$ for zeolite $\mathrm{X}$ ), are isostructural to the natural mineral, faujasite (Breck, 1974). The structure is essentially a diamond lattice of sodalite cages connected via the double-six-membered rings (D6R) of $\mathrm{SiO}_{4}^{4-}$ and $\mathrm{AlO}_{4}^{5-}$. By this connection, three cages are present: D6R, sodalite cage, and supercage. Alkali cations, which compensate the negative charges of the framework due to isomorphous substitution of Si by $\mathrm{Al}$, are distributed among at least four kinds of sites: site I in the center of the D6R cage, site I' inside the sodalite cage, site II on the wall of supercage, and site III above the four-membered ring in the supercage $[36,37]$. The occupation of the cation 

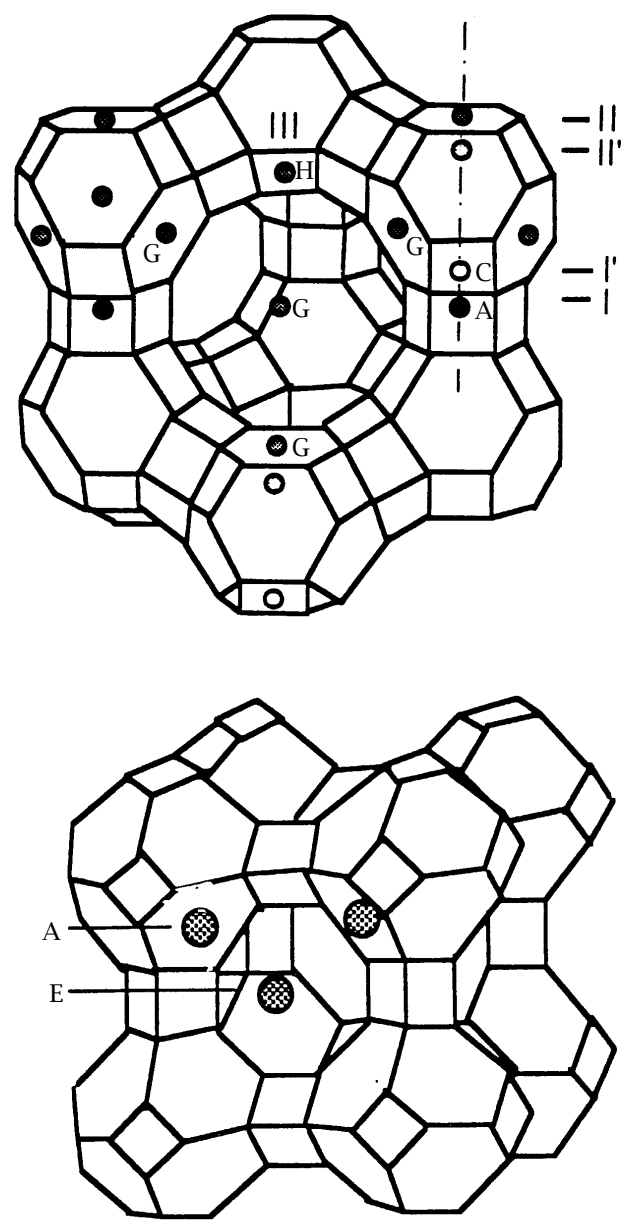

Figure 1. Structures of zeolites $Y$ and A.

sites depends on the nature of the cations and on the conditions under which the samples are treated. In dehydrated zeolites $\mathrm{X}$ and $\mathrm{Y}$, each sodalite cage contains four $\mathrm{Na}^{-}$ions in the type- $\mathrm{I}^{\prime}$ sites, and each supercage also contains $\mathrm{Na}^{-}$in the type-II sites. Foreign cations present in NaY occupy preferentially the cation sites; for example, $\mathrm{Cu}^{2+}$ and $\mathrm{Cd}^{2+}$ prefer the site I' $[38,39]$, while $\mathrm{Tl}^{-}$prefers the site III [40]. On complete hydration, water molecules fill the spaces of the cages, generally on average a total of $\sim 4$ water molecules in the sodalite cage, $\sim 24$ in the $\alpha$-cage of $\mathrm{NaA}$, and $34 \sim 37$ in the supercage of $\mathrm{NaY}$ and $\mathrm{NaX}$ [1]. The water molecules are randomly located in the supercage of $\mathrm{NaX}$ and $\mathrm{NaY}$ but structured (pentagonal dodecahedron in the $\alpha$-cage of $\mathrm{NaA}$.

For all the chemistry cited above the following events and situations in zeolites need to be known.

(1) What is it like "inside" a zeolite, i.e., environment.

(2) How do guest molecules move in zeolites, i.e., diffusion and factors controlling diffusion.

(3) What special reactions can you create in zeolites.
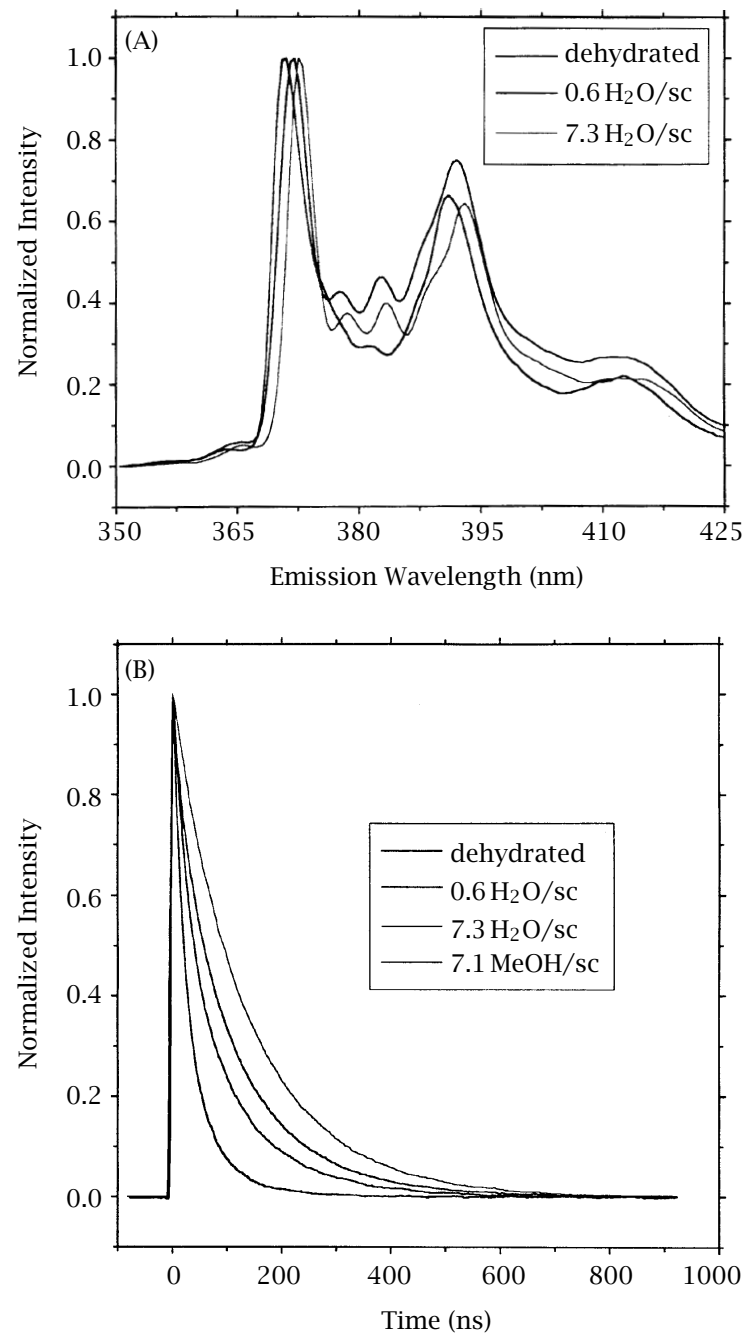

Figure 2. (A) Fluorescence spectra of $2 \mathrm{mM}$ pyrene in zeolite $Y$, with and without water. $\lambda$ excitation $=337 \mathrm{~nm}$, band pass $10 \mathrm{~nm}$. Insert top to bottom shows spectra left to right. (B) Decay of pyrene fluorescences in zeolite $Y$, with and without added water and methanol. $\lambda$ excitation = $337.1 \mathrm{~nm}, 0.4 \mathrm{~ns}$ pulses. Insert shows decays top to bottom.

(4) Can the microstructure of the zeolite be used to create nano-clusters?

\section{EXPERIMENTAL PROCEDURES}

All experimental procedure for zeolite handling and photochemical and spectroscopic techniques have been published in the appropriate references given.

\subsection{Environment and Cage to Cage Diffusion of} Guest Molecules. Figure 2(A) shows the fluorescence spectra of pyrene in zeolite $\mathrm{Y}$ with and without added water. It was previously shown [41] that the pyrene fluorescence fine structure depends on its environment. 
In dry zeolite $\mathrm{KY}$, the fine structure (III/I ratio) is low, and is indicative of a very polar environment. Addition of water increases this ratio to that exhibited in bulk water. The fluorescence lifetime (Figure 2(B)) shows a similar effect on addition of water, namely $\tau$ increases. Methanol also alters the pyrene fluorescence, and data indicative of methanol are observed. These experiments faithfully monitor the environment of pyrene in the microenvironment of the zeolite. Additional experiments where fluorescence quenchers are also present monitors the movement of the quenchers in the zeolite. Movement of many quenchers is slow and it is best to monitor the triplet state of the arene in order to measure cage to cage diffusion.

\section{CAGE TO CAGE DIFFUSION}

Laser flash photolysis of arenes adsorbed in zeolites give rise, following intersystem crossing, to the triplet state of the arene. This exhibits long life-times in zeolites (> ms). Hence, the slow diffusion of quenchers and/or arenes in the system can be monitored [42]. Figure 3(A) shows the decay of triplet pyrene with and without the quencher ferrocene, and with and without water. This figure shows a great increase in the rate with co-adsorbed ferrocene and a marked effect of water. Figure 3(B) shows the unusual effect of water on the rate of quenching of the pyrene triplet by ferrocene. Addition of up to 4 water molcules markedly enhances the rate, while further addition of water reduces it to a low level. Addition of $\mathrm{C}_{6} \mathrm{H}_{12}$ has little effect.

The reasons for these events are:

(a) Pyrene adsorbs to site II of the zeolite, at the interface of the sodalite cage with the supercage. A strong polar interaction is observed (see fluorescence section).

(b) Initial addition of water is to the $\mathrm{Na}^{+}$ions in the sodalite cage (up to 4 water). This weakens the arene interaction with the cage, and higher mobility is observed.

(c) Further addition of water is to the supercage, where motion is blocked.

(d) $\mathrm{C}_{6} \mathrm{H}_{12}$ only locates in the supercage where a small blocking effect is observed.

Table 1 summarizes the data. The use of quaternary ammonium derivatives of quencher or probe arene, leads to immobiliation of the molecules due to ionic interaction with the negative centers of the zeolite. The table shows that small arenes diffuse more rapidly in the zeolite, due to hindrance in the necks connecting the supercages. Water has a marked effect on all systems.

The diffusion constants of the various species may be calculated using the Smouluchowski equation.
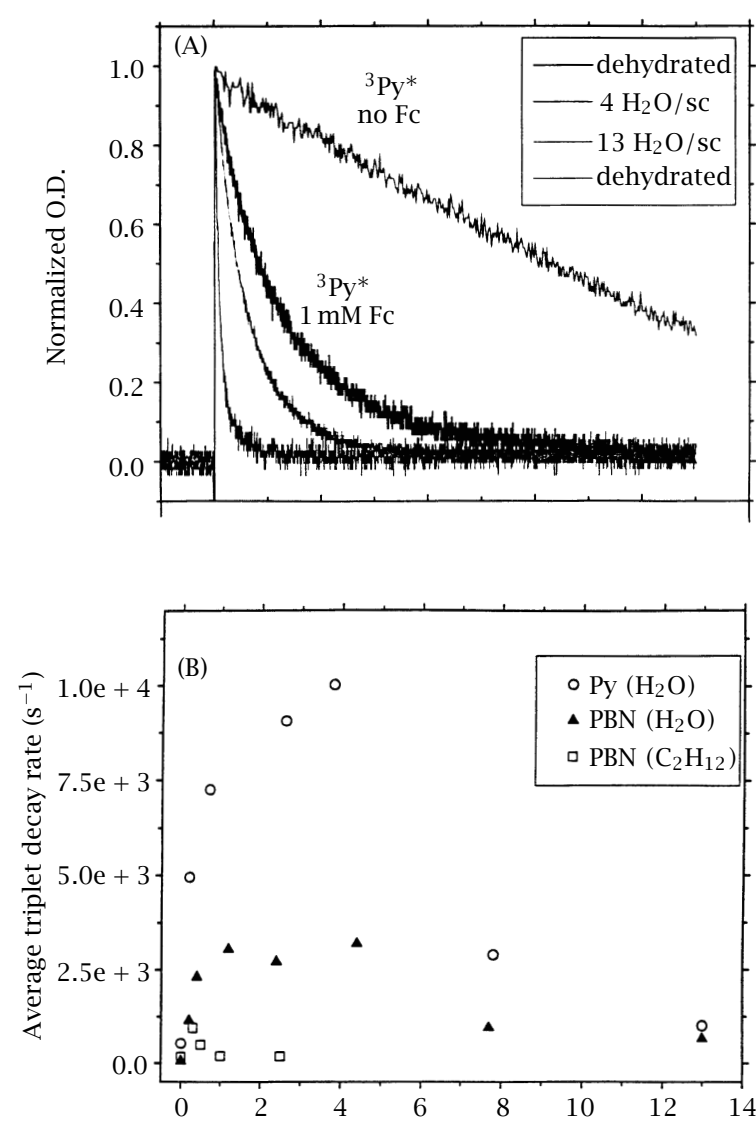

Figure 3. (A) Decay of pyrene (2 $\mathrm{mM})$ triplet in zeolite $Y$ without and without $1 \mathrm{mM}$ ferrocene, and with and without water. $\lambda$ excitation $=337.1 \mathrm{~nm}, 04 \mathrm{~ns}$ pulses. Insert shows decays bottom to top. (B) Effect of $\mathrm{H}_{2} \mathrm{O}$ and cyclohexane on the decay rate of pyrene triplet in the above system, pyrene $2 \mathrm{mM}$. Also pyrene butyl trimethyl ammomium choride (PBN),

Table 1. Rate of triplet quenching by Fc or FcMN in Zeolite $\mathrm{KY}$ and its dependence on added $\mathrm{H}_{2} \mathrm{O}$.

\begin{tabular}{llll}
\hline \multirow{2}{*}{ reaction } & \multicolumn{3}{c}{ quenching rate $\left(\mathrm{s}^{-1} \mathrm{M}^{-1}\right)^{\mathrm{a}}$} \\
\cline { 2 - 4 } & dehydrated & $4 \mathrm{H}_{2} \mathrm{O} / \mathrm{sc}$ & $13 \mathrm{H}_{2} \mathrm{O} / \mathrm{sc}$ \\
\hline${ }^{3} \mathrm{Py}^{*}+\mathrm{Fc}$ & $6 \times 10^{5}(1.3)$ & $1.4 \times 10^{7}(1.6)$ & $1.5 \times 10^{6}(5.5)$ \\
${ }^{3} \mathrm{Py}^{*}+\mathrm{FcMN}$ & $10^{2}(8000)$ & $2.2 \times 10^{5}(105)$ & $6.2 \times 10^{4}(134)$ \\
${ }^{3} \mathrm{Ph}^{*}+\mathrm{FcMN}$ & $1 \times 10^{5}(8)$ & $6.1 \times 10^{6}(3.8)$ & $2.0 \times 10^{6}(4.2)$ \\
${ }^{3} \mathrm{~Np}^{*}+\mathrm{FcMN}$ & $8 \times 10^{5}(1)$ & $2.3 \times 10^{7}(1)$ & $8.3 \times 10^{6}(1)$ \\
\hline
\end{tabular}

a Numbers in parentheses refer to the quenching rate of the reaction ${ }^{3} \mathrm{~Np}^{*}+$ FcMN divided by the quenching rate of the given reaction.

Hence, a $k$ of $10^{2} \mathrm{M}^{-1} \mathrm{~s}^{-1}$ leads to a cage to cage movement torr of $\sim 0.1 \mathrm{sec}$, while a $k$ of $10^{7}$ gives a torr of $10^{-6} \mathrm{sec}$.

These are relatively long time scales, and it is pertinent to inquire regarding dynamic motion in the actual supercages themselves. 


\section{DYNAMICS IN SUPERCAGES}

A view of the dynamics of guest molecules in the supercages can be obtained by studying the isomerization of trans-stilbene. The fluorescence lifetime of this molecules is short, $\sim 70 \mathrm{ps}$ in common solvents, but increases in viscous media. Two main processes occur, the excited state fluoreses in competition with the isomerization. Typical data as shown in Figure 4 for the fluorescence decay of trans-stilbene in various solvents. The response of the system is of the order of the fluorescence lifetime $(70 \mathrm{psec})$ and a special phase shift method is used to measure the fluorescence lifetimes [43]. Table 2 gave the fluorescence lifetime of t-stilbene in various solvents, a comparison with literature values, and values in zeolites under different conditions.

These data show that a narrow channel zeolite such as ZSM-5 gives long fluorescence lifetimes (2 > 500 ps)

The decay of trans-Stilbene fluorescence in Zeolites
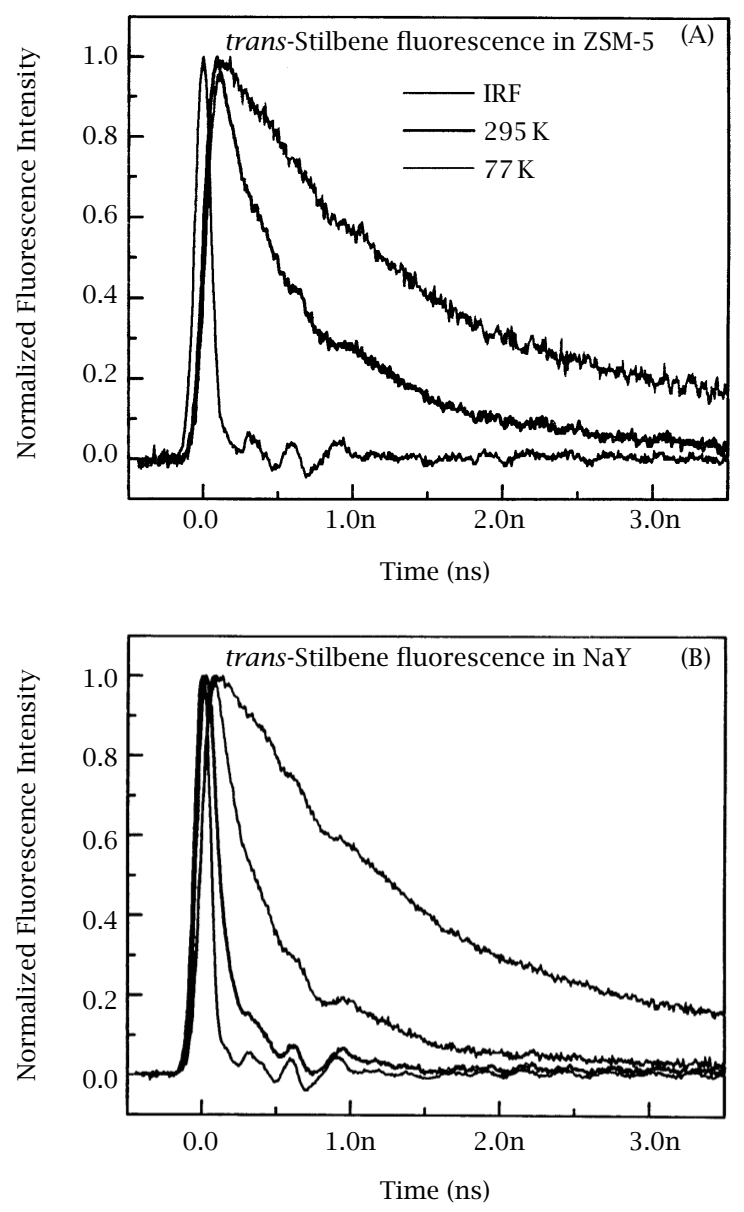

Figure 4. (A) Decay of trans-stilbene fluorescence in ZSM-5. $\lambda$ excitation $=355 \mathrm{~nm}, 20 \mathrm{psec}$ pulses. Insert indicates traces bottom to top. (B) Decay of trans-stilbene fluorescence in NaY. as the t-stilbene is restricted in these media. Lowering the temperature of the zeolite-stilbene system to $77^{\circ} \mathrm{K}$ also produces long $\tau$. All these data show restricted motion of stilbene in the zeolites and in other zeolites at $77^{\circ} \mathrm{K}$. At room temperature, zeolite NaY and $\mathrm{KY}$ give $\tau$ which are similar to those seen in low viscosity liquids such as cyclohexane. This indicates considerable motion in the sub-nanosecond time regime. Co-absorption of solvents causes restricted motion, i.e., long $\tau$. Such data are invaluable in discussing photo-induced reaction in zeolites.

\section{PHOTOIONIZATION IN ZEOLITES}

Transient absorption methods show that trapped ions, radical cations, radical anions, and other exotic trapped species, e.g., $\mathrm{Na}_{4}^{3+}$ etc., and solvated electrons can be created in zeolites X, Y, and A [18]. The lifetime of the ions are long, and can be minutes. This is a unique feature of the zeolite where it stabilizes photo-induced charged species. It is also pertinent to note that many of the events are one photon (photon energy $\sim 3.5 \mathrm{ev}$ ) and occur at energies well below the gas phase ionization threshold. One of the most important and unique species produced is the electron trapped in alkali metal cations. These species are most conveniently studied by pulse radiolysis methods, where the electron is produced by excitation of the zeolite framework itself.

Table 2. Room-temperature fluorescence lifetimes of trans-stilbene. Pre-determined literature values are given in parenthesis.

\begin{tabular}{|c|c|}
\hline Medium & Fluorescence lifetime (ps) \\
\hline Hexane & $66(70 \pm 8)[13]$ \\
\hline Methylcyclohexane & 62 \\
\hline Hexadecane & $127(157)[14]$ \\
\hline Glycerin & $580^{\dagger}$ \\
\hline ZSM-5 & $590^{\dagger}$ \\
\hline ZSM-5 (77K) & $1.5 \mathrm{~ns}^{\dagger}$ \\
\hline \multicolumn{2}{|l|}{ NaY (5 mM trans-Stilbene) } \\
\hline solvent-free & 52 \\
\hline $4 \mathrm{H}_{2} \mathrm{O} / \mathrm{sc}$ & 53 \\
\hline $13 \mathrm{H}_{2} \mathrm{O} / \mathrm{sc}$ & 22 \\
\hline $\mathrm{H}_{2} \mathrm{O}$ bath & $210,195^{\dagger}$ \\
\hline 1 cyclohexane/sc & 71 \\
\hline 2.5 cyclohexane/sc & 105 \\
\hline cyclohexane bath & $275,258^{\dagger}$ \\
\hline solvent-free $(77 \mathrm{~K})$ & $1.4 \mathrm{~ns}^{\dagger}$ \\
\hline \multicolumn{2}{|l|}{ NaY (100 mM trans-Stilbene) } \\
\hline solvent-free & 28 \\
\hline 2.5 cyclohexane/sc & 54 \\
\hline cyclohexane bath & 165 \\
\hline \multicolumn{2}{|l|}{ KY (5 mM trans-Stilbene) } \\
\hline solvent-free & 54 \\
\hline $4 \mathrm{H}_{2} \mathrm{O} / \mathrm{sc}$ & 57 \\
\hline $13 \mathrm{H}_{2} \mathrm{O} / \mathrm{sc}$ & 30 \\
\hline
\end{tabular}


The positive hole which is also produced has no spectral absorption in the near U.V.-visible region. Hence, the trapped electron species are studied to great advantage.

\section{ALKALI METAL ION-ELECTRON SPECIES}

Electrons trapped by ion clusters in zeolite cavities normally have characteristic absorption in the UV-visible range $(400 \sim 800 \mathrm{~nm})$ [18]. The stability of $\mathrm{Na}_{4}^{3+}$ in $\mathrm{Na}_{55} \mathrm{Y}$ even at room temperature made it possible to measure its absorpton spectrum in the early studies. The transient nature of other ion cluster trapped electrons requires measurements taken either at low temperature (as the above ESR spectra show) or at a fast time scale right after their production but before its decay. Identification of visible absorption bands and assignment to specific ion clusters are facilitated in combination with ESR measurements. Spectroscopic properties of some commonly observed ion clusters trapped electrons are given in Table 2. These species have been reproducibly identified in separate experiments where they are produced by different excitation schemes.

ESR data suggests that the ion cluster trapped electron in $\mathrm{Na}_{80} \mathrm{X}$ is attributed to $\mathrm{Na}_{4}^{3-}$. Diffuse reflectance measurements at $77 \mathrm{~K}$ found a broad absorption band centered at $550 \mathrm{~nm}$ which is shown in Figure 5(A) together with its characteristic 13-line ESR spectrum. The same absorption spectrum was also observed in the time resolved mode when a $\mathrm{Na}_{80} \mathrm{X}$ sample is excited by the nanosecond electron beam.

Thermal annealing induced transformation of trapped electron spcies in $\mathrm{Na}_{12} \mathrm{~A}$ as revealed in the above ESR studies is also reflected from the change in the absorption spectra. A broad near IR absorption peaked around $750 \mathrm{~nm}$ in a NaA sample irradiated and measured at $77 \mathrm{~K}$ was attributed to $\mathrm{Na}_{2}^{+}$. After annealing at $196 \mathrm{~K}$, the near IR spectrum is replaced by a new spectrum with its maximum at $640 \mathrm{~nm}$. Corresponding change in the ESR spectra were also recorded under the same condition, which clearly shows that a new band centered at $640 \mathrm{~nm}$ is due to $\mathrm{Na}_{3}^{2+}$ and that the transformation from $\mathrm{Na}_{2}^{+}$to $\mathrm{Na}_{3}^{2+}$ leads to the spectral shift. Both absorption spectra and corresponding ESR spectra are presented in Figure 5(B) at the two different temperatures.

\section{SOLVENT TRAPPED ELECTRONS IN ZEOLITES}

Water adsorbed into zeolites interacts strongly with both framework and alkali cations and significantly modifies the system. On the one hand, the solvation and redistribution of the charge balancing cations results in destruction of those ion cluster trapping sites identified in dehydrated zeolites. On the other hand, water confined by the rigid framework gives rise to chemistry similar to that observed in aqueous solutions but in a nanometer dimension.
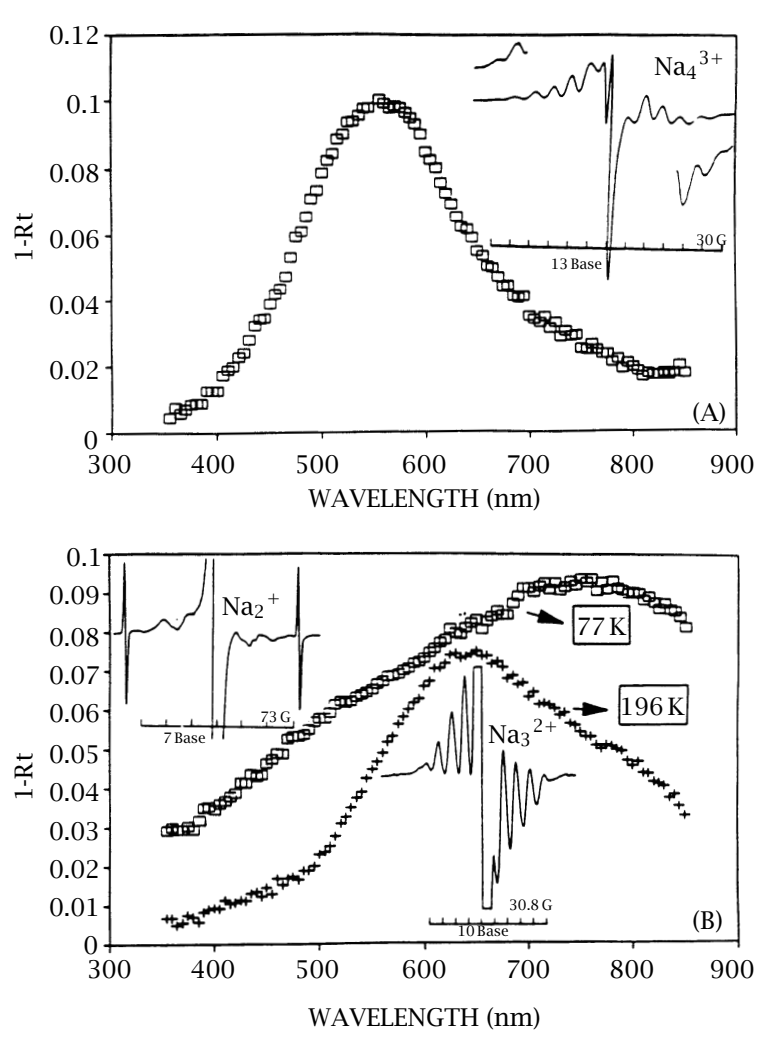

Figure 5. (A) Absorption spectrum of $\mathrm{Na}_{4}^{3+}$ and in $\mathrm{NaY}$. Insert EPR spectrum of $\mathrm{Na}_{4}^{3+}$. The curves from top to bottom and, $77 \mathrm{~K}$; room temperature; excess cyclohexane; IRF. (B) Absorption spectrum of $\mathrm{Na}_{3}^{2+}$ and $\mathrm{Na}_{2}^{+}$in sodalite. Inserts show EPR spectra of these species.

The formation of hydrated electrons (denoted as $\mathrm{e}_{\mathrm{S}}^{-}$ to distinguish it from $\mathrm{e}_{\mathrm{aq}}^{-}$in bulk water) in the zeolites $\mathrm{X}$ and $\mathrm{Y}$ has been identified by their absorption spectra, their short lifetimes distinct from the long lived cation cluster trapped electrons, and their characteristic reactions with electron quenchers such as $\mathrm{O}_{2}, \mathrm{~N}_{2} \mathrm{O}$, and $\mathrm{MV}^{2+}$ [18]. The results given below provide more detailed information about the nature of electron solvation in zeolite confined water clusters.

Figure 6 shows the transient absorption spectra of hydrated zeolites $\mathrm{Y}(2.5)$ and $\mathrm{X}(1.4)$ recorded at $\sim 20 \mathrm{~ns}$ after the electron pulse. For each of the zeolite samples, a series of spectra are measured upon removal of water by vacuum pumping. The spectral scan starts with zeolite samples equilibrated under 12 mbar water vapor where the supercage is completely filled with water. For convenience, the number of water molecules in a pseudo unit cell (a sodalite cage plus a supercage) will be used to denote the water content in a zeolite sample, which is 38 for zeolite $\mathrm{Y}$, and 41 for zeolite $\mathrm{X}$, as illustrated in the figure. The spectra of $38 \mathrm{H}_{2} \mathrm{O}$ hydrated $\mathrm{NaY}$ and $41 \mathrm{H}_{2} \mathrm{O}$ hydrated $\mathrm{NaX}$ (i.e., at the highest water content) exhibit nearly the same absorption 


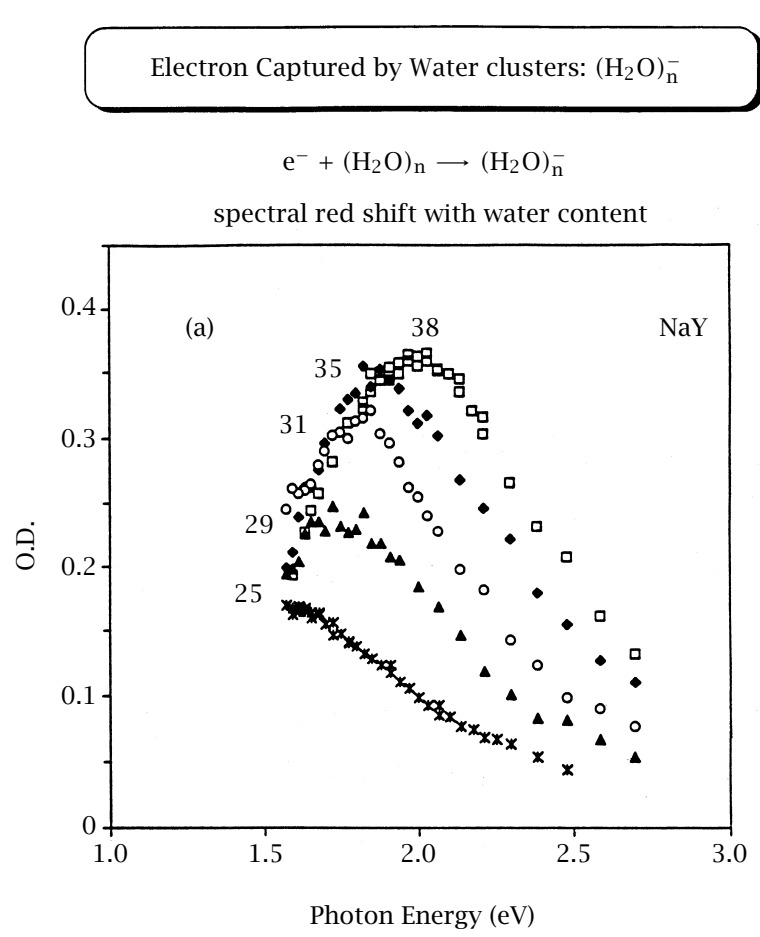

Figure 6. Absorption spectra of hydrated electrons $\mathrm{e}_{\mathrm{eq}}^{-}$in water pools in the super cages of $\mathrm{NaY}$.

peak around $2.0 \mathrm{eV}$ with a full width of $\sim 0.8 \mathrm{eV}$ at half maximum. On successive removal of water from the zeolites, a gradual spectral shift toward the longer wavelengths (i.e., lower transition energies) is observed, which is accompanied by a reduction in the intensity of the absorption bands. The half band widths at the high energy wing are around $0.5 \mathrm{eV}$ and correspond for all the spectra in zeolites $\mathrm{X}$ and $\mathrm{Y}$. No spectral broadening is observed, indicating that the water clusters have a uniform size in zeolites at different water contents.

The spectral red shift with the decreasing water content in zeolites exhibits some similarity with the water cluster anions in the gas phase.

Comparison of what is observed in hydrated zeolites with the gas phase results, shows that the water exists in the form of clusters in the cage structures of zeolites. The red shift of the transient absorption spectra of the water cluster trapped electrons in the zeolite supercage is a consequence of the decrease in cluster size upon dehydration. This exactly parallels that observed for $\left(\mathrm{H}_{2} \mathrm{O}\right)_{\mathrm{n}}^{-}$in the gas phase. The similarity in the spectral shape and the oscillator strength among water cluster trapped electrons in zeolites, $\mathrm{e}_{\mathrm{aq}}^{-}$in the liquid water, and in $\left(\mathrm{H}_{2} \mathrm{O}\right)_{\mathrm{n}}^{-}$the gas phase is indicative of the same origin of the involved electronic transition in the absorption spectra. Similar data have been observed for alcohol clusters in zeolites.

\section{CONCLUSION}

Zeolites provide unique well organised systems for the study of catalysed photochemical reactions, and to confined discrete $\mathrm{nm}$ dimension solvent pools. The various effects of zeolites on the photochemistry of adsorbed molecules is interpreted in the light of what is established for these photo systems in the bulk liquid phase. Zeolites also create unique alkali-metal cation clusters which markedly modify the photo-chemistry of molecules in their vicinity.

\section{ACKNOWLEDGEMENT}

The author wishes to thank the National Science Foundation for support of the work. Eric Ellison and Guohong Zhang deserve special thanks for all their participation in this work.

\section{References}

[1] D. W. Breck, Zeolite Molecular Sieves: Structure, Chemistry and Use, John Wiley \& Sons, New York, 1974.

[2] N. Y. Chen, Molecular Transport and Reaction in Zeolites: Design and Application of Shape Selective Catalysis, VCH, New York, 1994.

[3] R. M. Barrer, Zeolites and Clay Minerals as Sorbents and Molecular Sieves, Academic Press, London, 1978.

[4] S. Bhatia, Zeolite Catalysis: Principles and Applications, CRS Press, Boca Raton, FL, 1990.

[5] J. K. Thomas, Chem. Rev. 93 (1993), 301.

[6] G. Calzaferri, R. Giovanoli, I. Kamber, V. Shklover, and R. Nesper, Res. Chem. Intermed. 19 (1993), 31.

[7] L. R. M. Martens, P. J. Grobet, and P. A. Jacobs, Nature 315 (1985), 568. L. R. M. Martens, P. J. Grobet, W. J. M. Vermerien, and P. A. Jacobs, Proc. 7th Int. Zeolite Conf., 1986, p. 935. L. R. M. Martens, W. J. M. Vermerien, P. J. Grobet, and P. A. Jacobs, Stud. Surf. Sci. Catal. 31(1987), 531.

[8] P. P. Edwards, P. A. Anderson, and J. M. Thomas, Acc. Chem. Res. 29 (1996), 23.

[9] M. Iwamoto, K. Maruyama, N. Yamazoe, and T. Seiyama, J. Phys. Chem. 81 (1977), 622. M. Iwamoto, H. Yahiro, K. Tanda, N Mizuno, Y. Mine, and S. Kagawa, J. Phys. Chem. 95 (1991), 3727.

[10] P. H. Kasai, J. Chem. Phys. 43 (1965), 3323. J. A. Rabo, C. L. Angell, P. H. Kasai, and V. Schomaker, Discuss. Faraday Soc. 41 (1966), 328. P. H. Kasai and R. J. Bishop, Jr., J. Phys. Chem. 77 (1973), 2308. P. H. Kasai and R. J. Bishop, Jr., ACS Monogr. 171 (1976), 350.

[11] R. M. Barrer and J. F. Cole, J. Phys. Chem. Solids 29 (1968), 1755.

[12] T. Sun and K. Seff, Chem. Rev. 94 (1994), 857.

[13] V. I. Srdanov, K. Haug, H. Metiu, and G. D. Stucky, J. Phys. Chem. 96 (1992), 9039. N. P. Blake, V. I. 
Srdanov, G. D. Stucky, and H. Metiu, J. Phys. Chem. 99 (1995), 2127.

[14] P. P. Edwards, M. R. Harrision, J. Klinowski, S. Ramdas, J. M. Thomas, D. C. Johnson, and C. J. Page, J. Chem. Soc., Chem. Commun. (1984), 982. M. R. Harrison, P. P. Edwards, J. Klinowski, D. C. Johnson, and C. J. Page, J. Solid State Chem. 54 (1984), 530. P. A. Anderson, R. J. Singer, and P. P. Edwards, J. Chem. Soc. Chem. Commun. (1991), 914. P. A. Anderson and P. P. Edwards, J. Chem. Soc. Chem. Commun. (1991), 915. P. A. Anderson, D. Barr, and P. P. Edwards, Angew. Chem., Int. Ed. Engl. 30 (1991), 1501.

[15] U. Westphal and G. Z. Geismar, Anorg. Allg. Chem. 508 (1984), 165. J. B. A. F. Smeulders, M. A. Hefni, A. A. K. Klaassen, E. de Boer, U. Westphal, and G. Geismar, Zeolites 7 (1987), 347. R. E. H. Breuer, E. de Boer, and G. Geismar, Zeolites 9 (1989), 336.

[16] B. Xu and L. Kevan, J. Chem. Soc., Faraday Trans. 87 (1) (1991), 2843. B. Xu and L. Kevan, J. Chem. Soc., Faraday Trans. 87 (1991), 3157. K. B. Yoon and J. K. Kochi, J. Chem. Soc., Chem. Commun. (1988), 510. Y. S. Park, Y. S. Lee, and K. B. Yoon, J. Am. Chem. Soc. 115 (1993), 12220.

[17] G. A. Kuranova, High Energy Chem. 25 (1991), 91.

[18] K.-K. Iu and J. K. Thomas, J. Phys. Chem. 95 (1991), 506. K.-K. Iu and J. K. Thomas, Colloids Surf. 63 (1992), 39. X. Liu and J. K. Thomas, Chem. Phys. Lett. 192 (1992), 555. X. Liu and J. K. Thomas, Langmuir 8 (1992), 1750. K.-K. Iu, X. Liu, and J. K. Thomas, J. Phys. Chem. 97 (1993), 8165. X. Liu, K.-K. Iu, and J. K. Thomas, Chem. Phys. Lett. 224 (1994), 31.

[19] X. Liu, K.-K. Iu, and J. K. Thomas, J. Phys. Chem. 98 (1994), 13720.

[20] X. Liu, G. Zhang, and J. K. Thomas, J. Phys. Chem. 99 (1995), 10024.

[21] M. V. Barnabus and A. D. Trifunac, Chem. Phys. Lett. 187, (1991) 565. M. V. Barnabus and A. D. Trifunac, Chem. Phys. Lett. 193 (1992), 298. M. V. Barabus, D. W. Werst, and A. D. Trifunac, Chem. Phys. Lett. 204 (1993), 435. M. V. Barnabus, D. W. Werst, and A. D. Trifunac, Chem. Phys. Lett. 206 (1993), 21. K. R. Cromack, D. W. Werst, M. V. Barnabus, and A. D. Trifunac, Chem. Phys. Lett. 218 (1994), 485. D. W. Werst, E. E. Tartakovsky, E. A. Piocos, and A. D. Trifunac, J. Phys. Chem. 98 (1994), 10249.

[22] N. Turro, J. Acct. Chem. Res. 33 (2000), 637. N. J. Turro, Molecular Dynamics in Restricted Geometries, J. Klafter and J. M. Drake (eds.), John Wiley and Sons, New York, 1989, chapt. 14. V. Ramamurthy, Photochemistry in Organized and Constrained Media, V. Ramamurthy (ed.), VCH Publishers, Inc., New York, 1991, chapt. 10. J. K. Thomas, Chem. Rev. 93 (1993), 301. J. C. Scaiano and H. Garcia, Acc. Chem. Res. 32 (1999), 783.
F. Blatter, H. Sun, S. Vasenkov, and H. Frei, Catalysis Today 41 (1998), 297. H. Frei, F. Blatter, and S. Hai, CHEMTECH 26 (1996), 24.

[23] J. V. Caspar, V. Ramamurthy, and D. R. Corbin, Coordination Chemistry Reviews 97 (1990), 225. V. Ramamurthy, J. V. Caspar, D. F. Eaton, E. W. Kuo, and D. R. Corbin, J. Am. Chem. Soc. 114 (1992), 3882.

[24] S. Hashimoto, Chem. Phys. Lett. 252 (1996), 236. S. Hashimoto, T. Mutoho, H. Fukumura, and H. Masuhara, J. Chem. Soc., Faraday Trans. 92 (1996), 3653. S. Hashimoto, J. Chem. Soc., Faraday Trans. 93 (1997), 4401.

[25] V. Ramamurthy, P. Lakshminarasimhan, C. P. Grey, and L. Johnston, J. Chem. Comm. 22 (1998), 2411. L. Brancaleon, D. Brousmiche, V. J. Rao, L. J. Johnston, V. Ramamurthy, J. Am. Chem. Soc. 120 (1998), 4926.

[26] F. L. Cozens, H. Garcia, and J. C. Scaiano, Langmuir 10 (1994), 2246. M. Alvaro, H. Garcia, S. Garcia, F. Marquez, and J. C. Scaiano, J. Phys. Chem. B 101 (1997), 3043.

[27] K. K. Iu and J. K. Thmas, Langmuir 6 (1990), 471. X. Liu, K. K. Iu, and J. K. Thomas, J. Phys. Chem. 93 (1989), 4120.

[28] G. Calzaferri, Chimia 52 (1998), 525.

[29] S. Uppili, K. J. Thomas, E. Crompton, and V. Ramamurthy, Langmuir 16 (2000), 265.

[30] K. K. Iu, X. Liu, and J. K. Thomas, Mat. Res. Soc. Symp. Proc. 233 (1991), 119.

[31] V. Ramamurthy, D. R. Sanderson, and D. F. Eaton, J. Phys. Chem. 97 (1993), 13380.

[32] S. Hashimoto, S. Ikuta, T. Ashai, and H. Masuhara, Langmuir 14 (1998), 4284.

[33] F. L. Cozens, M. Regimbald, H. Garcia, and J. C. Scaiano, J. Phys. Chem. 100 (1996), 18165.

[34] K. J. Thomas, R.B. Sunoj, J. Chandrasekhar, and V. Ramamurthy, Langmuir 16 (2000), 4912.

[35] S. Hashimoto, N. Hagiwara, T. Asahi, and H. Masuhara, Langmuir 15 (1999), 3123.

[36] G. H. Eulenberger, D. P. Shoemaker, and J. G. Keil, J. Phys. Chem. 71 (1967), 1812.

[37] D. W. Breck, J. Chem. Educ. 41 (1964), 678.

[38] P. Gallezot, Y. Ben Taait, and B. Imelik, J. Catal. 26 (1972), 295.

[39] D. H. Strome and K. Klier, J. Phys. Chem. 84 (1980), 981.

[40] V. Gramlich and W. M. Z. Meier, Kristallogr. 133 (1971), 134. Guohong Zhang et al., L. McMurray, A. J. Holmes, A. Kuperman, G. A. Ozin, and S. Ozkar, J. Phys. Chem. 95 (1991), 9448.

[41] K. Kalyanasundaram and J. K. Thomas, JACS 99 (1977), 2039.

[42] E. Ellison, J. Phys. Chem. 103 (1999), 9314.

[43] E. Ellison and J. K. Thomas, J. Phys. Chem. (2001), in press. 


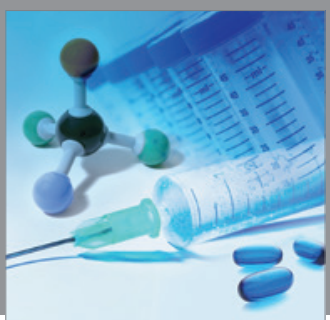

International Journal of

Medicinal Chemistry

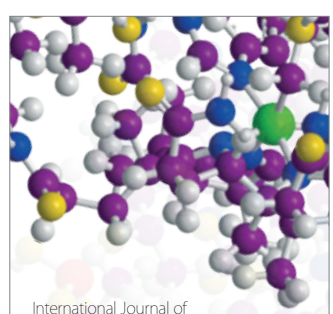

Carbohydrate Chemistry

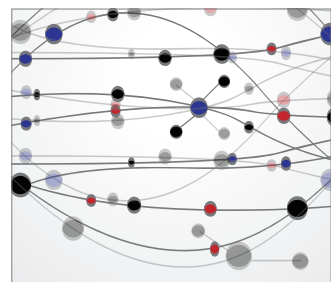

The Scientific World Journal
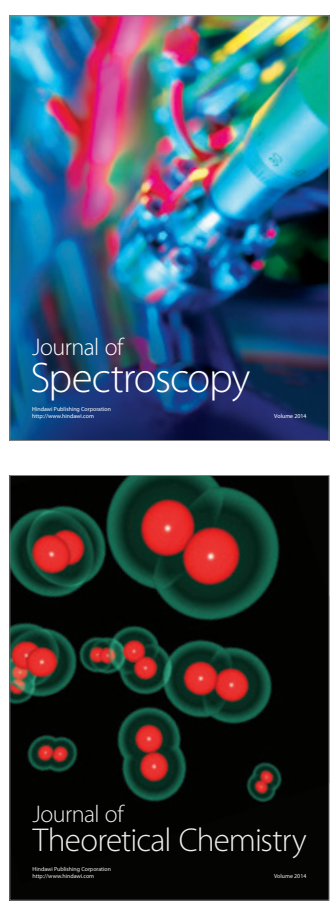
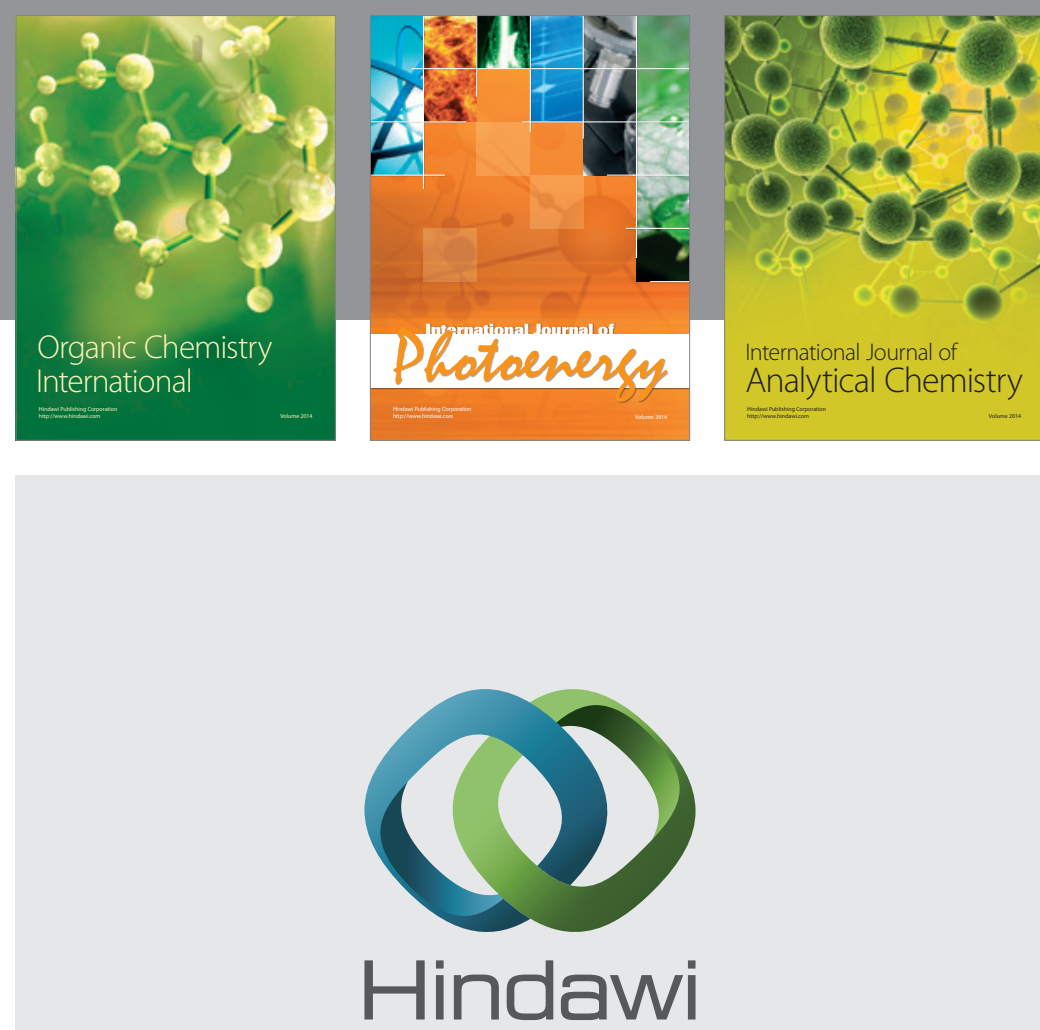

Submit your manuscripts at

http://www.hindawi.com
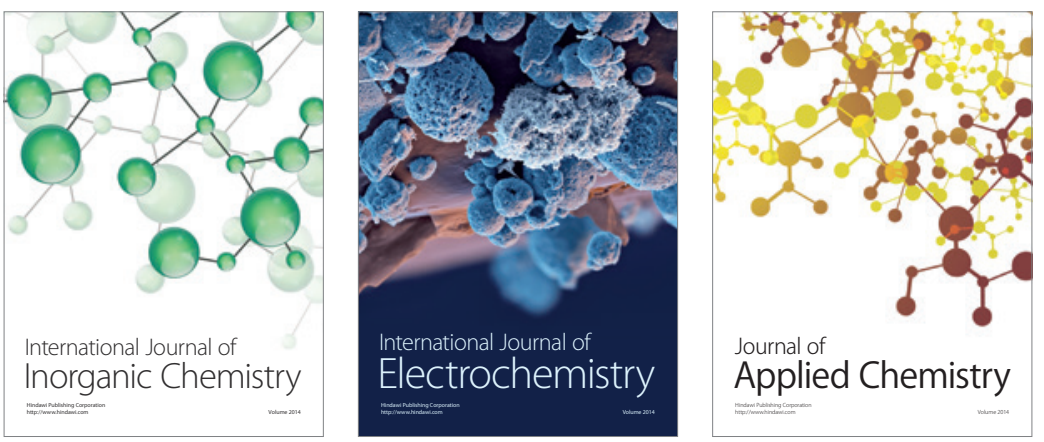

Journal of

Applied Chemistry
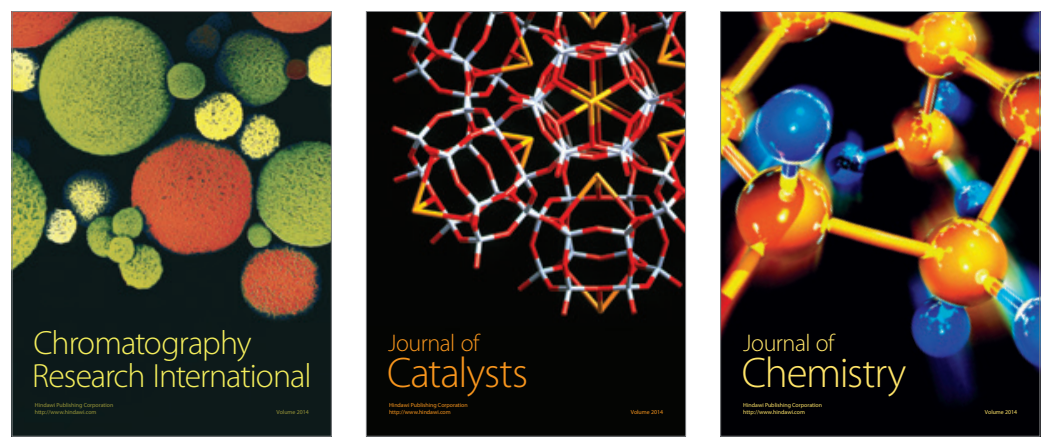
